\title{
PERCEPÇÕES VALORATIVAS DE PRÁTICAS EM BANCO DE LEITE HUMANO*
}

\author{
Tuâny Figueiredo Marinho ${ }^{1}$, Valdecyr Herdy Alves², Maria Bertilla Lutterbach Riker Branco ${ }^{3}$, Diego Pereira \\ Rodrigues $^{4}$, Rosângela de Mattos Pereira ${ }^{3}$, Giovanna Rosario Soanno Marchiori ${ }^{5}$
}

RESUMO: O estudo objetivou identificar e analisar as percepções valorativas dos profissionais de saúde que atuam no Banco de Leite Humano sobre suas práticas. Trata-se de estudo descritivo de natureza qualitativa, cujos participantes foram 24 profissionais de saúde atuantes em Banco de Leite Humano do estado do Rio de Janeiro. A coleta de dados foi realizada nos meses de julho de 2012 a fevereiro de 2013 por intermédio de entrevista semiestruturada. $\mathrm{Na}$ análise de conteúdo temática dos depoimentos, emergiram três categorias: A prática de orientação do aleitamento materno; Doação, pasteurização e distribuição do leite humano: cuidado nutricional; e Afetividade no aleitamento materno como facilitador do vínculo mãe-filho. Os profissionais entrevistados demonstram satisfação com o trabalho que realizam e com o envolvimento em todas as atividades pertinentes ao Banco de Leite Humano.

DESCRITORES: Aleitamento materno; Leite humano; Saúde da mulher; Obstetrícia.

\section{VALUE PERCEPTIONS OF PRACTICES AT A HUMAN MILK BANK}

ABSTRACT: This study was aimed at identifying and analyzing the value perceptions of health professionals working at the Human Milk Bank about their practices. A descriptive and qualitative study was undertaken. The participants were 24 health professionals working at a Human Milk Bank in the state of Rio de Janeiro. The data were collected between July 2012 and February 2013 through semistructured interviews. In the thematic content analysis of the testimonies, three categories emerged: The practice of guiding breastfeeding; Human milk donation, pasteurization and distribution: nutritional care; and Affection in breastfeeding as a facilitator of the mother-child bond. The interviewed professionals demonstrate satisfaction with their work and with the engagement in all activities relevant to the Human Milk Bank.

DESCRIPTORS: Breast feeding; Milk, human; Women's health; Obstetrics.

\section{PERCEPCIONES VALORATIVAS DE PRÁCTICAS EN BANCO DE LECHE HUMANA}

RESUMEN: El objetivo del estudio fue identificar y analizar las percepciones valorativas de los profesionales de salud que actúan en el Banco de Leche Humano sobre sus prácticas. Se trata de estudio descriptivo del tipo cualitativo, cuyos participantes fueron 24 profesionales de salud que actúan en Banco de Leche Humana del estado de Rio de Janeiro. Los datos fueron recolectados entre julio del 2012 y febrero del 2013 mediante entrevista semiestructurada. En el análisis de contenido temático de los testimonios, emergieron tres categorías: La práctica de orientación de la lactancia materna; Donación, pasteurización y distribución de la leche humana: cuidado nutricional; y Afectividad en la lactancia materna como facilitador del vínculo madre-hijo. Los profesionales entrevistados demuestran satisfacción con el trabajo que efectúan y con el involucramiento en todas las actividades pertinentes al Banco de Leche Humana.

DESCRIPTORES: Lactancia materna; Leche humana; Salud de la mujer; Obstetricia.

\footnotetext{
*Artigo extraído de dissertação intitulada: “A práxis dos profissionais de saúde na promoção, proteção e apoio ao aleitamento materno nos Bancos de Leite Humano do Estado do Rio de Janeiro". Universidade Federal Fluminense, 2013.

${ }^{1}$ Enfermeira. Hospital Municipal Miguel Couto. Niterói, RJ, Brasil.

²Enfermeiro. Doutor em Enfermagem. Docente de Enfermagem da Universidade Federal Fluminense. Niterói, RJ, Brasil.

${ }^{3}$ Enfermeira. Mestre em Saúde Materno Infantil. Hospital Universitário Antônio Pedro da Universidade Federal Fluminense. Niterói, RJ, Brasil.

${ }^{4}$ Enfermeiro. Mestrando em Ciências do Cuidado da Saúde. Docente do Centro Universitário Anhanguera. Rio de Janeiro, RJ, Brasil.

${ }^{5}$ Enfermeira. Mestre em Saúde Materno Infantil. Docente da Faculdade Novo Milênio. Espírito Santo, ES, Brasil.
}

\author{
Autor Correspondente: \\ Diego Pereira Rodrigues \\ Universidade Federal Fluminense \\ R. Desembargador Leopoldo Muylaert, 307 - 24350-450 - Niterói, RJ, Brasil \\ E-mail: diego.pereira.rodrigues@gmail.com
}




\section{INTRODUÇÃO}

O ato de amamentar é milenar, sem custo e essencial para o ser humano, não apenas determinado por aspectos naturais e biológicos, mas também construído pelo cotidiano das famílias nos seus ambientes sociais e culturais ${ }^{(1-2)}$.

Amamentar é dar de mamar; criar ao peito; aleitar; lactar; alimentar, nutrir. Já aleitamento é sinônimo de amamentação, sob o ponto de vista da sua definição, revestido da mesma conotação funcional do aleitar ou criar o filho com o leite que produz. Portanto, o significado de ambas as palavras não fica restrito ao aspecto puramente biológico da ação; ao contrário, ultrapassa-o por traduzir as emoções que envolvem o relacionamento da mulher com o seu filho, a família e o mundo que os cerca ${ }^{(2-3)}$.

O aleitamento materno é fonte ideal de nutrição para o bebê, devendo ser exclusivo até os seis meses de vida e complementar até os dois anos ${ }^{(4)}$. As ações de promoção ao aleitamento materno devem ser instituídas desde o início do pré-natal, pois o despreparo da puérpera para aleitar muitas vezes gera sentimentos de impotência que podem levar ao desmame precoce. Os profissionais que atuam nos espaços dos Bancos de Leite Humano (BLH) oferecem apoio às mulheres e seus familiares para que o aleitamento materno seja facilitado ${ }^{(5-6)}$.

Em 1943 surge o primeiro BLH, tendo como objetivo inicial coletar o leite humano e redistribuí-lo para recém-nascidos prematuros e/ou com patologias. Ao longo de décadas de estudos e desenvolvimento tecnológico, o BLH torna-se uma política com normas técnicas instituídas e importante parceiro na Política Nacional de Aleitamento Materno no Brasil( ${ }^{(7)}$.

A partir da década de oitenta, é intensificada a prática do aleitamento materno, que passa a ser valorizado principalmente como recurso de diminuição das taxas de mortalidade infantil. O BLH, então, amplia sua missão para atender a saúde da mulher e da criança mediante parcerias com esferas públicas e privadas, doravante tornando-se responsável pelas ações de promoção, proteção e apoio ao aleitamento materno; coleta do leite humano, seleção, classificação e processamento de leite humano ${ }^{(7)}$.

Nesse contexto, o BLH deve estar inserido na prática da amamentação com a nutriz, bebê, família e comunidade, promovendo uma linha de cuidado ao binômio materno-infantil e contribuindo para a promoção, apoio e proteção da amamentação(8).

Nas ações dos BLH, se por um lado o Ministério da Saúde defende a amamentação como alimentação ótima para as crianças pequenas, que é o objetivo maior da política pública, por outro lado, esta prática envolve personagens (mãe, bebê e família) cujas subjetividades precisam ser consideradas em suas respectivas singularidades, exigindo que os profissionais de saúde estejam preparados para isso ${ }^{(9)}$.

As práticas profissionais direcionadas à amamentação visam estimular o aleitamento materno exclusivo até os seis primeiros meses de vida, e complementar até os dois anos ou mais, observando e corrigindo alguns problemas comuns como erro de pega, problemas de sucção, insegurança materna, como também prevenindo infecções mamilares e mastites que podem interferir no estabelecimento de amamentação saudável e favorecer o desmame precoce ${ }^{(4,10)}$.

A prática de amamentação, sob a ótica dos profissionais que atuam nos BLH do estado do Rio de Janeiro, possibilitará identificar o quanto valorizam suas ações, visto estar constatado que eles atuam em grande demanda com tecnologia leve e dependem, em grande medida, de suas disponibilidades emocionais para realizar suas ações a contento. Assim, o estudo teve como objetivo: identificar e analisar as percepções valorativas dos profissionais de saúde que atuam no BLH em relação às suas práticas.

\section{- MÉTODO}

Pesquisa descritiva de natureza qualitativa, realizada em cinco BLH do estado do Rio de Janeiro, sendo escolhido um BLH como representante de cada sub-região estadual. Na região onde havia mais de um BLH, houve sorteio para essa escolha, a saber: Região Serrana - BLH do Hospital Maternidade 
Nova Friburgo; Norte Fluminense - BLH do Hospital dos Plantadores de Cana; Médio Paraíba - BLH do Hospital São João Batista; Região Metropolitana I - BLH Nutricionista Gilsara do Bonfim Santos; e Região Metropolitana II - BLH do Hospital Universitário Antônio Pedro.

Os cenários foram os 5 BLH acima citados, e a coleta das informações deu-se durante os meses de julho de 2012 a fevereiro de 2013, utilizando-se como técnica a entrevista semiestruturada baseada em roteiro com perguntas abertas e fechadas. As entrevistas foram áudio gravadas com anuência dos entrevistados.

Os participantes do estudo foram vinte e quatro (24) profissionais de saúde dos BLH, escolhidos de forma aleatória simples, à medida que foram atendidos os seguintes critérios de inclusão: prestar assistência no BLH no mínimo há seis meses; e apresentar interesse em participar da pesquisa. As categorias profissionais dos participantes totalizaram: dez Técnicas de Enfermagem, seis Enfermeiras, duas Nutricionistas, duas Médicas, uma Bióloga, uma Fisioterapeuta, um Técnico de Laboratório e uma Técnica de Nutrição.

A busca por novos depoimentos foi interrompida quando da saturação, por repetição, das informações coletadas. Os participantes foram identificados como Profissionais e receberam um código alfanumérico sequencial (P1, P2,...P24) para assegurar o sigilo e o anonimato do respectivo depoimento.

A pesquisa foi aprovada pelo Comitê de Ética em Pesquisa do Hospital Universitário Antônio Pedro, sob protocolo $\mathrm{n}^{\circ}$ 191-2011, e as entrevistas foram realizadas após assinatura do Termo de Consentimento Livre e Esclarecido (TCLE).

A transcrição dos depoimentos foi submetida aos entrevistados para validação, antes da realização da análise de conteúdo, que tem como etapas: pré-análise com leitura flutuante do material coletado, constituição de corpus dos dados, leitura aprofundada e identificação de unidades de contexto e de registro. Após essas etapas, realizou-se a exploração do material e, finalmente, o tratamento dos resultados ${ }^{(11)}$.

\section{RESUlTADOS}

\section{A prática de orientação do aleitamento materno}

Em primeira análise, pode-se afirmar que a orientação para o aleitamento materno é valorada pelos profissionais de saúde, sendo este valor resultante do conhecimento adquirido e transmitido às mães, conforme consta em seus depoimentos:

Quando a gente chega aqui, dá informação, dá conselho, faz aconselhamento para amamentar, que é o melhor para o seu filho, que estimula bastante, a gente estimula mesmo. (P3)

O mais importante é incentivar o aleitamento materno. É procurar tirar as dúvidas das mães, gosto também de ir na enfermaria e por os bebês para mamar, ter aquele manejo. (P24)

Ainda versando sobre orientação, destaca-se sua importância durante o pré-natal para o sucesso da lactação:

Mas uma coisa que eu procuro saber com as mulheres que chegam para nós muitas vezes, é se fizeram o pré-natal aqui mesmo, se elas receberam essa orientação durante o pré-natal. A gente está até com um projeto de fazer uns encontros, para que esta mulher receba as orientações no momento propício. (P10)

Emergiu dos depoimentos de alguns profissionais a orientação/informação com foco na resolução prática de problemas:

Então, eu acho assim: é importante o atendimento à mãe/mulher, porque o nosso produto é o leite, é o aleitamento materno, fazer com que a maior parte das mulheres de toda a Metro II consigam amamentar de uma forma mais tranquila e saber resolver as situações. (P9) 


\section{Doação, pasteurização e distribuição do leite humano: cuidado nutricional}

É importante destacar que os profissionais de saúde diretamente relacionados com a captação, processamento e controle de qualidade do leite humano expressam o valor dessa prática, que é uma das formas de segurança alimentar:

Também a importância da coleta desse leite junto às doadoras, o processamento desse leite e o controle de qualidade desse leite, para os prematuros da Neonatal. (P3)

Bom, eu como nutricionista tenho essa visão diferenciada dos enfermeiros. Então, assim, dentro da minha visão, é claro que eu vejo muito o lado do fator nutricional, sem dúvida. (P5)

Então, tudo aqui é importante, desde a coleta, o processamento, a distribuição. (P24)

\section{A afetividade no aleitamento materno como facilitador do vínculo mãe-filho}

A valorização da afetividade e do apoio emocional à amamentação na prática do profissional atuante no BLH, é expressa no depoimento a seguir:

Eu saí de uma grande emergência, de uma sala de sutura, então, eu fui de um extremo ao outro. Eu lidava com o vermelho e hoje estou lidando com o branco. Eu lidava com a constante morte, e agora eu lido com a constante vida. Eu lido com o branco, branco do sorriso, branco do leite, eu vou para casa com boas imagens, hoje eu não me vejo trabalhando em outro lugar que não fosse aqui. (P17)

Mesmo quando agrupados na mesma categoria temática, os depoimentos dos profissionais citam a importância do valor afetivo na prática, que surge fortemente na relação deles com a mãe; outros valoram a relação da mãe com seu bebê; e outros ainda valoram o trabalho em si, como demonstram suas falas:

O que eu acho mais importante é fazer com que as mulheres tenham segurança naquilo que elas fazem, então, elas vão valorizar todas as orientações de quem está em volta. Coloco sempre para elas: a amamentação é um processo que acontece entre você e o bebê. A minha função aqui é promover a integração mamãe/bebê, afinar a relação mamãe/bebê, vocês dois vão se encaixar, você e o seu bebê. Eu sempre valorizo ela. (P14)

O que eu acho mais importante do meu trabalho? Eu acho que é a maneira com que às vezes eu trato as mãezinhas. Tem aquele carinho, entendeu? Isso é hiper gratificante. Não tem preço, é muito legal, é muito legal mesmo! Adoro. (P15)

O depoimento a seguir expressa, além da percepção valorativa de afeto do profissional como prática cotidiana, uma ideia de condicionalidade da maternidade à amamentação:

Acho que é o prazer de estar ajudando aquela vida que acabou de nascer, a estar mamando, a estar junto com a mãe, eu acho o sorriso daquela mãe quando: Ai, eu consegui! Eu sou mãe de verdade! E quando eu saí da casa da mãe, ela falou assim: Você me deu o melhor presente de Dia das Mães que eu podia ganhar, que era o meu filho amamentando. Eu saí rápido porque eu ia chorar no meio do caminho. O meu prazer é muito grande de estar vendo aquela criança ali mamar, aquela mãe feliz, eu não posso nem explicar, mas é uma coisa que vem do coração mesmo. Eu faço uma coisa que eu gosto de fazer. $(P 7)$

\section{- DISCUSSÃO}

Constata-se que os profissionais de saúde dos BLH utilizam a orientação para promover a prática do aleitamento materno, tão preconizada pelo Ministério da Saúde, mas que tem se mostrado um desafio para todos os envolvidos nessa orientação, resultando em baixos índices de aleitamento exclusivo e complementado necessitando, portanto, do comprometimento político e institucional para incentivar essa prática e favorecer a diminuição dos índices de mortalidade infantil(12-13).

No Brasil, políticas públicas voltadas para o aleitamento materno como Rede Amamenta Brasil; 
Iniciativa Hospital Amigo da Criança (IHAC); Método Canguru; Rede Brasileira de BLH; proteção legal através da Norma Brasileira para Comercialização de Alimentos para Lactentes e Crianças de Primeira Infância (NBCAL); ações de mobilização social, através de campanhas e parcerias e monitoramento pelo Ministério da Saúde das ações e práticas de aleitamento materno, têm possibilitado redesenho na prática dos profissionais de saúde dos BLH, favorecendo a conscientização da mulher-nutriz acerca da importância da amamentação, por intermédio de informações e de aconselhamento, permitindo mudança importante no painel da amamentação no país ${ }^{(1,5-6)}$.

A educação e o preparo das mulheres para a lactação comprovadamente contribuem para o sucesso do aleitamento materno. É durante a assistência pré-natal que as mulheres devem ser orientadas acerca dos benefícios da amamentação, das desvantagens do uso de leites não humanos, além de serem informadas a respeito das técnicas apropriadas à amamentação, contribuindo com o seu manejo e confiança $\mathrm{a}^{(2,5-6,10,14)}$.

Nesse sentido, o profissional de saúde valoriza a promoção e o apoio do aleitamento materno, oferecendo as orientações necessárias para uma prática adequada, inibindo os riscos dos agravos à saúde da mulher nas questões de posição e pega mamária ${ }^{(14)}$. Contudo, ressalta-se o reconhecimento dos profissionais atuantes no BLH acerca da importância dessas orientações durante o pré-natal.

O olhar para a resolução de problemas demonstra engajamento dos profissionais do BLH, o que se configura de extrema relevância, já que dois dos fatores que contribuíram para o afastamento da mulher da prática de aleitar, durante o século XX, foram a desvalorização desse ato pelos próprios profissionais de saúde e a falta de orientações e informações corretas sobre essa questão. Tais fatos tiveram significativo reflexo no aumento da mortalidade infanti $\left.\right|^{(1-2,15)}$.

A prática dos profissionais de saúde dos BLH deve estar pautada na redução dos riscos relacionados ao aleitamento materno, tais como: ingurgitamento mamário, mastite, dor mamilar, abscesso mamário, dentre outros. Além disso, esse profissional atua como um facilitador do aleitamento materno, sendo fundamental o seu conhecimento relacionado aos aspectos que dificultem ou facilitem o estabelecimento e a manutenção da lactação ${ }^{(16-17)}$. Esta constatação esteve presente nos discursos dos entrevistados nesta pesquisa.

Nessa perspectiva, as recomendações das políticas públicas de aleitamento materno afirmam que, para atuar nos espaços do BLH, o profissional de saúde deve estar capacitado para a realização das ações propostas, a exemplo da captação de leite humano, que depende de campanhas de divulgação e conscientização da população de nutrizes para que façam doação, sendo esta uma das práticas imperativas para o atendimento de demandas dos recém-nascidos prematuros e/ou com alguma patologia. Não é demais lembrar que o leite humano proporciona uma combinação única de proteínas, lipídeos, minerais, vitaminas, enzimas e células de proteção imunológica, constituindo benefícios nutricionais e imunológicos reconhecidos e inquestionáveis para a segurança alimentar da criança ${ }^{(18-19)}$.

Nesse sentido, os profissionais de saúde do BLH valoram o processo de doação do leite humano, considerado extremamente importante para a saúde infantil, bem como a coleta, o processamento e a distribuição desse leite, cujo valor nutricional ratificam em suas práticas. A valorização da questão nutricional do leite humano demonstra ainda a preocupação e o cuidado que os profissionais dispensam aos bebês internados nas Unidades de Terapia Intensiva Neonatais, face à importância de nutri-los de maneira eficiente.

Os profissionais de saúde que atuam nos espaços do BLH não devem ser apenas técnicos hábeis, mas também capazes de conseguir manter um relacionamento afetuoso com a mãe, a fim de que sua experiência e prática cotidiana contribuam significativamente para o apoio ao aleitamento materno, promovendo com isso a saúde emocional da mulher ${ }^{(20)}$. Nesta pesquisa o relacionamento com as mães foi valorizado entre os entrevistados.

Quando o atendimento realizado nos BLH é humanizado, permeado por ações de incentivo à prática do aleitamento materno, a afetividade e a criação de vínculo de confiança no processo de comunicação possibilitam aos profissionais de saúde exercerem papel multiplicador junto aos seus relacionamentos sociais, disseminando informações e valores que favorecem o engajamento de novas mulheres doadoras na promoção e apoio ao aleitamento materno ${ }^{(18)}$. 
A prática dos profissionais de saúde mostra que a captação de doadoras de leite humano não está desvinculada de um olhar no cuidado com a mãe e o bebê ${ }^{(18)}$. Na visita domiciliar citada em depoimento, por exemplo, eles deixam de ser simples coletores de leite, quando prestam apoio ao aleitamento materno e contribuem para o aumento dos seus índices.

As equipes que atuam nesses BLH são multidisciplinares; logo, tem importância fundamental para o funcionamento pleno dessas Unidades porque beneficiam e qualificam as atividades que desenvolvem no apoio ao aleitamento materno. Nesse sentido, os conselhos e opiniões de pessoas próximas e de profissionais de saúde são elementos significativos na avaliação da saúde e bem estar materno e infantil(20).

Ademais, o apoio ao aleitamento materno deve ser incentivado, pois essa prática contribui com a amamentação e inibe o desmame precoce. Fica evidente que é fundamental a participação desses profissionais como agentes no processo do manejo clínico da amamentação, cabendo-lhes observar e intervir de forma adequada no processo da lactação junto às mulheres nutrizes, recém-nascidos e famílias, mostrando-lhes o caminho para o sucesso do aleitamento materno.

A interação é compreendida como alicerce para o desenvolvimento adequado das relações interpessoais, que se estabelece de forma dual e gradual, profissional/mulher; mãe-bebê, profissional/ práticas. Isso constitui um valor para a prática do aleitamento materno. Logo, esse laço afetivo deve, sempre que possível, ser estável e harmônico, a fim de que se previnam possíveis ameaças à construção do vínculo de apego entre os envolvidos ${ }^{(20)}$.

A construção do vínculo e sua valorização contribuem, como revelado nos depoimentos, para o surgimento de um sentimento de gratificação por um trabalho diário bem desenvolvido, relacionado com questões afetivas que asseguram o sucesso da ação profissional, proporcionando além da sua felicidade satisfação não só profissional, mas pessoal também.

Deve-se atentar quando a reação emotiva do profissional com as questões concernentes à amamentação é exacerbada e ele supervaloriza este processo, isto porque esse profissional passa a conceber a maternidade a partir da prática estabelecida do aleitamento materno, o que se mostra um pensamento reducionista do que vem a ser "mãe de verdade"(20).

Percebe-se o quanto as questões emocionais e afetivas estão presentes no fazer dos profissionais atuantes no BLH. Eles não valoram apenas a educação em saúde, a orientação, ou ainda o fator nutricional, mas consideram como mais importante em seus processos de trabalho o estabelecimento de vínculos criados na relação profissional-usuário, fortalecidos na relação mãe-bebê-família.

\section{CONSIDERAÇÕES FINAIS}

Neste estudo identificaram-se três categorias que sintetizaram as percepções valorativas dos profissionais de saúde atuantes nos BLH do estado do Rio de Janeiro: a orientação como prática do aleitamento materno; doação, pasteurização e distribuição do leite humano: cuidado nutricional; a afetividade no aleitamento materno como facilitador do vínculo mãe-filho. Nelas, os profissionais demonstraram a satisfação no trabalho que realizam, o envolvimento com todas as atividades pertinentes ao BLH, ainda que cada profissional tenha seu campo de atuação e não execute cada uma delas individualmente.

Constata-se que um dos valores mais expressos por estes profissionais sobre a respectiva prática diz respeito às questões emocionais. A construção de vínculo, as relações de afeto, a sensibilidade, o prazer no que se faz, a possibilidade de contribuir com a harmonização da tríade mãe-bebê-família e com o empoderamento da mãe-nutriz, são as facetas mais atraentes para o profissional que atua no $\mathrm{BLH}$.

Desta forma, eles contribuem para que essa Unidade não seja apenas um espaço de armazenamento de leite ou uma escola do aleitar. A prática desses profissionais pode ser constatada a partir do que eles valoram, fazendo do BLH um cenário promotor de saúde para mães, bebês, famílias e comunidades e expressando a importante participação do papel do BLH no complexo e apaixonante movimento do aleitamento materno. 
Com isso, evidencia-se que a prática abrange mais que meramente processos fisiológicos de nutrição do bebê ou soluções como o manejo clínico da amamentação ou o processamento e controle de qualidade do leite humano. Os profissionais percebem que suas ações podem determinar melhores chances de qualidade de vida para tantas famílias que transitam pelos BLH apresentando suas incertezas frente às questões de alimentação infantil e do cuidado com as relações.

Como limitação do estudo, pontua-se a impossibilidade de manter contato com profissionais de saúde que estavam realizando alguns procedimentos no momento da coleta de dados, com isso reduzindo o número de participantes em um único cenário e impedindo a generalização dos achados da pesquisa.

\section{O REFERÊNCIAS}

1. Alves VH, Rodrigues DP, Branco MBLR, de Souza RMP, de Souza RRB, Medeiros FVA. Banco de leite humano na perspectiva da mulher doadora. Rev Rene. [Internet] 2013;14(6) [acesso em 12 ago 2016]. Disponível: http://dx.doi. org/10.15253/rev\%20rene.v14i6.3734.

2. Alves VH, Rodrigues DP, Cabrita BAC, Vieira BDG, Branco MBLR, de Sá AMP. Breastfeeding as an evaluative practice in know-how: a descriptive study. Online Braz J Nurs. [Internet] 2013;12(4) [acesso em 12 ago 2016]. Disponível: http://dx.doi.org/10.5935/1676-4285.20134154.

3. de Souza KV, Tesin RR, Alves VH. Mães de recém-nascidos hospitalizados: em/entre círculos no processo de amamentação. Acta paul. enferm. [Internet] 2010;23(5) [acesso em 12 ago 2016]. Disponível: http://dx.doi. org/10.1590/S0103-21002010000500004.

4. Machado MOF, de Paula MSR, Parreira BDM, Stefanello J, Sponholz FG. Comparação do conhecimento sobre o aleitamento materno entre mulheres no período pós-parto. Rev. Enferm. UERJ. [Internet] 2013;21(1) [acesso em 12 ago 2016]. Disponível: http://www.facenf.uerj.br/v21n1/v21n1a11.pdf.

5. Conceição CS, Alves VH, Silva LR, Martins CA, Mattos DV, Rodrigues DP. Quality care of the bank of human milk: the perception of users. Rev enferm UFPE on line. [Internet] 2013;7(5) [acesso em 12 ago 2016]. Disponível: http://www.revista.ufpe.br/revistaenfermagem/index.php/revista/article/download/4280/6351.

6. Ministério da Saúde (BR). Secretaria de Atenção à Saúde. Departamento de Ações Programáticas e Estratégicas. II Pesquisa de prevalência de aleitamento materno nas Capitais Brasileiras e Distrito Federal. Brasília: Editora do Ministério da Saúde; 2009.

7. Ministério da Saúde (BR). Agência Nacional de Vigilância Sanitária. Banco de Leite Humano: funcionamento, prevenção e controle de riscos. Brasília: Anvisa; 2008.

8. Valente GSC, Alves MRS, Andrade M, Ferreira SCM, Alves VH, Vilar AMA. The educational action of the nurse in home visit for collection of human milk: an experience report. Rev enferm UFPE on line. [Internet] 2012;6(11) [acesso em 10 jan 2016]. Disponível: http://www.revista.ufpe.br/revistaenfermagem/index.php/revista/article/ view/2818/pdf_1713.

9. Kalil IR, de Aguiar AC. Protagonista da amamentação ou instrumento da política de saúde infantil?: a enunciação da mulher nos materiais oficiais de promoção e orientação ao aleitamento materno. Saúde Soc. [Internet] 2016;25(1) [acesso em 10 jan 2016]. Disponível: http://dx.doi.org/10.1590/S0104-12902016139049.

10. Ministério da Saúde (BR). Secretaria de Atenção à Saúde. Departamento de Atenção Básica. Saúde da criança: nutrição infantil: aleitamento materno e alimentação complementar. Brasília: Editora do Ministério da Saúde: 2009.

11. Bardin L. Análise de conteúdo. $4^{\mathrm{a}}$ ed. Lisboa: Edições 70; 2009.

12. Potter PA, Perry AG. Fundamentos de enfermagem. $7^{\mathrm{a}}$ ed. Rio de Janeiro: Elsevier; 2009.

13. de Almeida GG, Spiri WC, Juliani CMCM, Paiva BSR. Proteção, promoção e apoio ao aleitamento materno em um hospital universitário. Ciênc. saúde coletiva. [Internet] 2008;13(2) [acesso em 10 jan 2016]. Disponível: http:// dx.doi.org/10.1590/S1413-81232008000200024. 
14. Demito MO, da Silva TC, Páschoa ARZ, Mathias TAF, Bercini LO. Orientações sobre amamentação na assistência pré-natal: uma revisão integrativa. Rev Rene. [Internet] 2010;11(n.esp) [acesso em 10 jan 2016]. Disponível: http:// www.revistarene.ufc.br/edicaoespecial/a25v11esp_n4.pdf.

15. Montenegro CAB, Rezende Filho J. Obstetrícia Fundamental. 12 ${ }^{\mathrm{a}}$ ed. Rio de Janeiro: Guanabara Koogan; 2011.

16. Ministério da Saúde (BR). Departamento de Ações Programáticas Estratégicas. Departamento de Atenção Básica Rede Amamenta Brasil: caderno do tutor. [Internet] Brasília; 2009 [acesso em 10 jan 2016]. Disponível: http://www.sbp.com.br/src/uploads/2012/12/caderno_tutores_rede_amamenta.pdf.

17. da Costa ARC, Teodoro TN, de Araújo MFM. Análise dos conhecimentos e da prática de profissionais de saúde na promoção e no apoio à amamentação: Estudo de revisão. Comum. ciênc. saúde. 2009;20(1):55-63.

18. de Alencar LCE, Seidl EMF. Doação de leite humano: experiência de mulheres doadoras. Rev. Saúde Pública. [Internet] 2009;43(1) [acesso em 10 jan 2016]. Disponível: http://dx.doi.org/10.1590/S0034-89102009000100009.

19. Neves LS, Sá MVM, Mattar MJG, Galisa MS. Doação de leite humano: dificuldades e fatores limitantes. O Mundo da Saúde. [Internet] 2011;35(2) [acesso em 10 jan 2016]. Disponível: http://www.saocamilo-sp.br/pdf/ mundo_saude/84/156-161.pdf.

20. Ministério da Saúde (BR). Grupo Hospitalar Conceição. Gerência de Saúde Comunitária. Atenção à saúde da criança de 0 a 12 anos. Brasília: Ministério da Saúde; 2009. 